\title{
Flower-size Heritability and Floral Heat-shock Tolerance in Diploid Roses
}

\author{
Shuyin Liang, Xuan Wu, and David Byrne ${ }^{1}$ \\ Department of Horticultural Sciences, Texas A\&M University, College \\ Station, TX 77843-2133
}

Additional index words. Rosa, abiotic stress, heat tolerance, heritability, genetic variance

\begin{abstract}
The effect of heat on rose flowers was examined by measuring flower size in 10 diploid rose populations created by crossing the heat-tolerant Texas A\&M University (TAMU) breeding lines (M4-4, J06-20-14-3) and sensitive (97/7-2, 'Red Fairy', 'Sweet Chariot', 'Vineyard Song', 'Old Blush', and 'Little Chief') diploid roses. As expected, the populations and individual seedlings differed in flower size. The heat-shock treatment (1 hour at $\left.44{ }^{\circ} \mathrm{C}\right)$ decreased flower diameter $(15.7 \%)$, petal number $(23.3 \%)$, and flower dry weight $(16.9 \%)$. Flower-size traits had moderately low narrow-sense $(0.24,0.12$, and 0.34 for flower diameter, petal number, and flower dry weight, respectively) and moderately high broad-sense $(\mathbf{0 . 6 2}, \mathbf{0 . 7 4}$, and 0.76 for flower diameter, petal number, and flower dry weight, respectively) heritability indicating important nonadditive genetic effects. If rose genotypes vary in floral heat tolerance, a differential response to heat among populations, seedlings, or both detected statistically by a significant interaction effect would be expected. Both the analysis of variance (ANOVA) and the restricted estimated maximum likelihood (REML) analyses showed a positive population $\times$ heat stress interaction effect for flower diameter. Although our data indicate differences in floral heat tolerance among the populations and genotypes, the effect was small as compared with the other sources of variation. Thus, using this 1-hour heat-shock approach would not be an effective strategy to select for floral heat tolerance in rose.
\end{abstract}

Roses (Rosa L.) for the past 5000 years have been one of the most popular flowers used as garden plants, cut flowers, and for the food, medicinal, and fragrance industries (Shepherd, 1954; Zlesak, 2006). They were originally domesticated in the Northern Hemisphere and have been spread throughout the world (Krussmann, 1981). This widely used ornamental crop has a diversity of plantgrowth habits and flower sizes, forms, colors, and fragrances.

The value of world rose production was estimated at 24 billion Euros in 2008 (Heinrichs, 2008), and the Dutch rose cut-flower market was estimated to be worth $\$ 10$ billion (Ahmad et al., 2010). Recently, the annual value of the North American landscape rose industry was estimated at $\$ 1$ billion (Vineland Research and Innovation Centre, 2013). Owing to the lack of well-adapted cultivars, garden rose sales have decreased from $25 \%$ to $30 \%$ during the past 20 years (Byrne et al., 2010; Hutton, 2012; Pemberton and Karlik, 2015).

Heat stress is one of the most significant abiotic stresses which negatively affects

Received for publication 13 Dec. 2016. Accepted for publication 15 Mar. 2017.

This work was partially funded by the Robert E. Basye Endowment in Rose Genetics and the USDA's National Institute of Food and Agriculture (NIFA) Specialty Crop Research Initiative projects, "RosBREED: Combining Disease Resistance with Horticultural Quality in New Rosaceous Cultivars" and "Combating Rose Rosette Disease: Short Term and Long Term Approaches." ${ }^{1}$ Corresponding author. E-mail: dbyrne@tamu.edu. landscape performance by causing leaf damage, flower abscission, and decreased flower size and quality. These effects greatly reduce the market value of garden roses. Heat or high temperature stress is one of the major limiting abiotic factors for plant growth throughout the world. Hence, a rose with high temperature tolerance and consistent flowering during the warm season would contribute toward maintaining an aesthetically pleasing landscape appearance (Greyvenstein et al., 2014).

Garden roses suffer from poor flower quality and decreasing flower yield due to high temperatures. Average daily maximum temperatures 8-14 d (about 2 weeks) before a flower opens significantly affects flower dry weight (Greyvenstein, 2013; Greyvenstein et al., 2014). Excessive heat stress may cause negative effects on the longevity and quality of a cut rose (Marissen, 2001; Moe, 1975; Wahid et al., 2007), as well as on flower size, petal number, flower color, flower number (by increasing flower abscission), number of vegetative nodes before flowering, time to flowering, or leaf appearance (Greyvenstein, 2013; Greyvenstein et al., 2014; Grossi et al., 2004; Shin et al., 2001). Thus far, differences in heat tolerance have been detected among rose cultivars in their ability to maintain consistent flower size and numerous flowers under heat stress in the field and in flower abscission and leaf necrosis in response to a heat-shock treatment $\left[3 \mathrm{~h}, 44{ }^{\circ} \mathrm{C}, 50 \%\right.$ relative humidity (RH)] (Greyvenstein, 2013; Greyvenstein et al., 2014), but little is known about the genetic basis of these differences. This study was to determine if differences in floral heat tolerance were detectable with a heat-shock treatment.

\section{Materials and Methods}

Plant material. Since 2010, the TAMU Rose Breeding and Genetics program has been assessing the ability of rose germplasm to produce flowers in the cool season (April, May, and November) as compared with the warm season (August) in Texas. Using this approach, roses such as 97/7-2, 'Red Fairy', 'Sweet Chariot', 'Vineyard Song', and 'Little Chief' were identified as very sensitive to high temperatures as they produced abundant flowers in the cool season, but produced few flowers during the warm season. In contrast, the rose breeding lines M4-4 and J06-20-14-3 produced abundant flowers throughout the year and thus were classified as heat tolerant with respect to their flower productivity. Five to ten seedlings from each of ten diploid rose populations developed by crossing heatsensitive ('97/7-2', 'Red Fairy', 'Sweet Chariot', 'Vineyard Song', 'Old Blush', and 'Little Chief') and heat-tolerant (M4-4 and J06-20-14-3) roses were asexually propagated by stem cuttings during the Fall 2013. Plants were grown in 2.7 L black plastic containers in a peat and perlite mixture (Metro-Mix Professional Growing Mixes; Sun Gro Horticulture Canada CM Ltd., Agawam, MA) and slow-release fertilizer (Osmocote 14-14-14; Scotts MiracleGro, Marysville, $\mathrm{OH}$ ) in the greenhouse (25/ $20{ }^{\circ} \mathrm{C}$ day/night) under natural photoperiods during Winter 2013 and Spring 2014 and then moved outside to the outdoor nursery until treatments were imposed.

On 15 Apr. 2015, plants were pruned back to a standard size (three nodes or $10 \mathrm{~cm}$ long stem without flowers or visible flower buds) to synchronize their flowering cycles (Fig. 1A). Plants were allowed to grow for 4 to 6 weeks in the greenhouse $\left(25 / 20{ }^{\circ} \mathrm{C}\right.$ day/night) under natural photoperiods until flower buds were visible (Fig. 1A and B) at which time the temperature treatments were imposed.

Experimental setup. The experiment was conducted using a randomized complete block design with three replications. Each replication had 160 plants consisting of 2 plants each of 80 unique genotypes. For each genotype, one plant was subjected to the heat-shock treatment $\left(44{ }^{\circ} \mathrm{C}\right.$ and $50 \% \mathrm{RH}$ for $1 \mathrm{~h}$ ), and the other remained in a fan-andpad-cooled greenhouse $\left(25 / 20^{\circ} \mathrm{C}\right.$ day/night). The heat-stress treatment was modified after Greyvenstein (2013) by reducing the exposure to $1 \mathrm{~h}$ instead of $3 \mathrm{~h}$ to avoid issues with flower abortion. All plants were well watered before treatment. After the treatment, all plants were placed in an outdoor container nursery (20-34/9-26 ${ }^{\circ} \mathrm{C}$ day/night) (NOAA, 2015), and data were collected on flower petal number, flower diameter, and flower dry weight 1-2 weeks after treatment or when the labeled flower fully opened (13 May 
2015-15 June 2015). Flower size was measured as flower diameter (centimeters), petal number, and dry weight (milligrams). Flower dry weight was taken after the whole flower without the pedicel was dried for at least $3 \mathrm{~d}$ at $80{ }^{\circ} \mathrm{C}$. The flower petal number included both full-size petals and petaloids. All labeled flowers were selected and labeled at the visible flower bud stage with white flagging (control) and colored flagging (heat-shock treatment) (Fig. 1A).

At least three flowers from the primary inflorescence were measured from each plant when the flower was fully open with dehiscing pollen, flower developmental stage 10 as described by Ma et al. (2015).

Statistical analysis. All statistical analyses were performed using JMP software (Version 12.0.1; SAS Institute Inc, Cary, NC). The Shapiro-Wilk W test was used to control for data normality. Student's $t$ test was used to separate the population means between the two treatments. In roses, the flower type of single (5-8 petals) vs. double flowers (petal number greater than 8 ) is controlled by a major gene with the double-type condition being a dominant gene (Debener, 1999). Thus, as the number of petals in single flowers does not vary throughout the year, only double flowers were considered in calculating the genetic variance of petal number.

The REML model $\left(y=\mu+\sigma_{\mathrm{FP}}^{2}+\sigma_{\mathrm{PP}}^{2}\right.$

$$
\begin{gathered}
+\sigma_{\text {Prog }[\mathrm{FP}, \mathrm{PP}]}^{2}+\sigma_{\text {Season }}^{2}+\sigma_{\text {Season }{ }^{*} \mathrm{FP}}^{2} \\
+\sigma_{\text {Season }{ }^{*} \mathrm{PP}}^{2}+\sigma_{\text {Season }{ }^{*} \operatorname{Prog}[\mathrm{FP}, \mathrm{PP}]}^{2}+ \\
\left.+\sigma_{\text {Error }}^{2}\right)
\end{gathered}
$$

$(\mathrm{FP}=$ female parent; $\mathrm{PP}=$ pollen parent $)$ was used to estimate genotypic and phenotypic variance and calculate narrow- and broadsense heritability. Heritability is the proportion of variance that is due to genetic components and can be used to determine the appropriate breeding approach. Heritability varies widely for the same trait in the same crop because of statistical designs, different environments, different populations, and different estimation methods (Bernardo, 2010). In this study, parental variances were regarded as additive variance $(V a)$, progeny variance was regarded as nonadditive variance $(V d)$, variance due to the heat shock and control treatments was regarded as environmental variance $(\mathrm{Ve})$, variance due to parents and progeny was regarded as genotypic variance $(V g)$, and the interaction of genotype and heat treatments was treated as genetic $\times$ environmental variance $(\mathrm{Vg} \times \mathrm{e})$ (Connor et al., 2005). The narrow-sense heritability, $h^{2}$, was calculated by $V a$ divided by phenotypic variance $(V p)$, where $V p=$ $V a+V d+\mathrm{Vg} \times e / e ; e$ indicates the number of environments (heat shock and control) (Hallauer et al., 2010; Holland et al., 2003). The broad-sense heritability, $H^{2}$, was calculated by the sum of $V a$ and $V d$ divided by the $V p$.

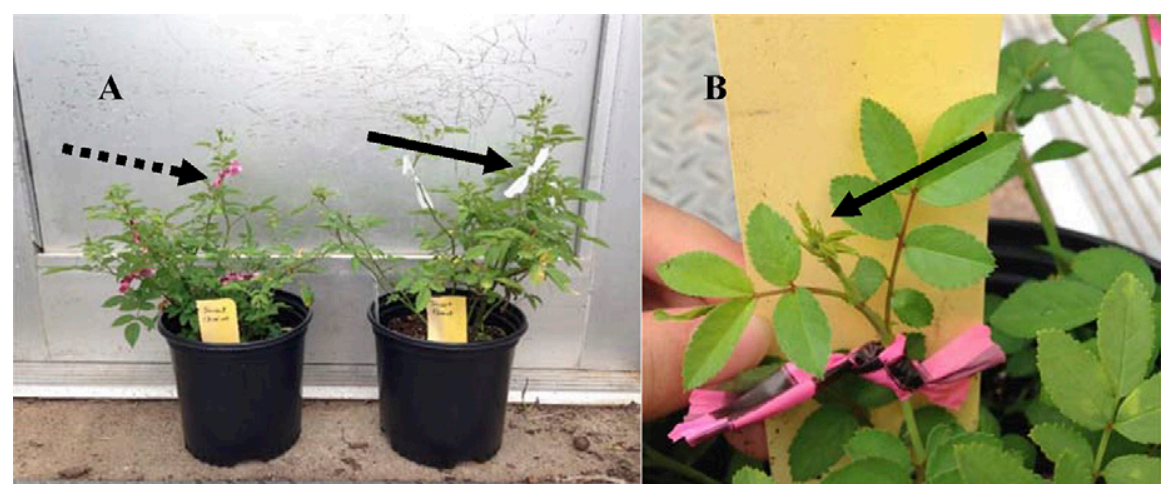

Fig. 1. Synchronized plants with visible flower bud ready for heat shock. (A) Visible flower bud labeled with white flagging (solid arrow) and colored flagging (dotted line arrow) indicate the control plant and the plant scheduled for heat-shock treatment, respectively. (B) Visible flower bud marked with solid arrow is ready for the heat-shock treatment.

\section{Results}

Normality analysis. The data normality was improved by transforming $\left(\log _{10}, \log _{\mathrm{e}}\right.$, and root transformation) the petal number and flower dry weight data but not the flower diameter data. Thus, the raw data of flower diameter and $\log _{10}$ transformed data of petal number and flower dry weight were used in the statistical analyses.

General linear analyses of flower diameter, petal number, and flower dry weight. Visible signs of stress were not seen until 2 weeks after the heat-shock treatment when some of the peduncles exhibited browning (Fig. 2). The flower size differed among populations and among the progeny within the populations, and the heat shock decreased all three measures of flower size (Tables 1 and 2).

Flower diameter among the plants ranged from $1.70 \mathrm{~cm}$ to $5.30 \mathrm{~cm}$ and among the population means ranged from $4.06 \mathrm{~cm}$ to $3.03 \mathrm{~cm}$. Mean flower diameter of populations differed with 'Old Blush' $\times$ M4-4 and J14$3 \times$ 'Vineyard Song' populations having the largest flower diameters and M4-4 × 97/7-2 and J14-3 $\times$ 'Little Chief' populations having the smallest flower diameters. In overall populations, average flower diameter for heat-stressed plants $(3.22 \mathrm{~cm})$ was $15.7 \%$ less than that of control plants $(3.82 \mathrm{~cm})$ (Table 1).

As only double-flowered genotypes were examined for petal number, there were few observations for populations 'Sweet Chariot' $x$ M4-4 and M4-4 × 97/7-2 and none from populations 'Sweet Chariot' $\times$ 97/7-2 and J14-3 $\times$ 'Vineyard Song'. Among the doubleflowered genotypes in the eight populations, the petal number ranged from 12 to 140 petals per flower. Mean petal number of populations differed $(P \leq 0.05)$ and ranged from 29 ('Old Blush' $\times$ M4-4) to 76 ('Sweet Chariot' $\times$ J14$3)$. Average petal number was decreased by $23.3 \%$ because of the heat-stress treatment (Table 1).

Flower dry weight ranged from $20 \mathrm{mg}$ (J14-3 $\times$ 'Little Chief', 'Sweet Chariot' $\times 97 /$ $7-2$, and M4-4 $\times 97 / 7-2$ ) to $210 \mathrm{mg}$ ('Old

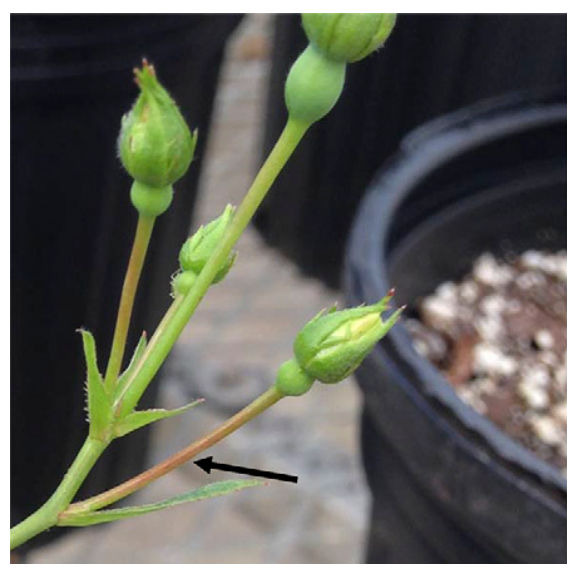

Fig. 2. Browning of rose peduncles caused by a $1-\mathrm{h}$ heat shock at $44{ }^{\circ} \mathrm{C}$ with $50 \%$ relative humidity when evaluated 2 weeks after treatment was occasionally observed.

Blush' $\times$ M4-4, J14-3 × 'Sweet Chariot', and 'Old Blush' $\times$ 'Red Fairy'). Mean flower dry weight among the ten populations differed and ranged from $41 \mathrm{mg}$ ('Sweet Chariot' $\times$ 97/7-2 and M4-4 × 97/7-2) to $100 \mathrm{mg}$ ('Sweet Chariot' $\times$ J14-3). Average flower dry weight of heat-stressed plants $(64 \mathrm{mg})$ was $16.9 \%$ lower than control plants $(77 \mathrm{mg})$ (Table 1).

As expected, there were large differences among populations, among progeny within populations, as well as a substantial decrease $(15.7 \%$ to $23.3 \%)$ in flower size because of the 1 -h heat-shock treatment at $44{ }^{\circ} \mathrm{C}$ (Table 1). With respect to the population by heat shock and progeny (nested in population) by heat-shock interactions, only flower diameter, but not petal number or flower dry weight, resulted in a significant interaction effect (Table 2). This interaction indicated that populations, on average, and progeny within populations responded differentially to the heat stress, which reflects differences among the germplasm in heat tolerance when measuring flower diameter. Among populations, the most heat tolerant was J14-3 $\times$ 'Sweet Chariot'. It only had a $9.9 \%$ decrease in flower diameter (Table 1). 
Table 1 . Heat shock $\left(1 \mathrm{~h}\right.$ at $44{ }^{\circ} \mathrm{C}$ with $50 \%$ relative humidity) effect on flower size of 10 diploid rose populations, $n=3$.

\begin{tabular}{|c|c|c|c|c|c|c|c|c|c|}
\hline \multirow[b]{2}{*}{ Parentage $^{x}$} & \multicolumn{3}{|c|}{ Flower diam ${ }^{\mathrm{z}}(\mathrm{cm})$} & \multicolumn{3}{|c|}{ Petal number ${ }^{y}$} & \multicolumn{3}{|c|}{ Flower dry wt (mg) } \\
\hline & Control & Heat stress & $\%$ decrease & Control & Heat stress & $\%$ decrease & Control & Heat stress & $\%$ decrease \\
\hline$\overline{\mathrm{OB}} \times \mathrm{M} 4-4$ & 4.41 & 3.66 & $17.0^{*}$ & 34 & 24 & 30.0 & 86 & 73 & 15.1 \\
\hline $\mathrm{SC} \times \mathrm{M} 4-4$ & 3.93 & 3.23 & $17.8^{*}$ & 61 & 60 & 1.4 & 54 & 48 & 11.2 \\
\hline $\mathrm{J} 14-3 \times \mathrm{VS}$ & 4.55 & 3.57 & $21.5^{*}$ & - & - & - & 80 & 54 & 32.0 \\
\hline $\mathrm{J} 14-3 \times \mathrm{SC}$ & 3.73 & 3.36 & $9.9 *$ & 60 & 50 & 16.6 & 92 & 73 & 20.4 \\
\hline $\mathrm{J} 14-3 \times \mathrm{LC}$ & 3.45 & 2.99 & $13.3 *$ & 62 & 37 & 41.4 & 66 & 58 & 12.7 \\
\hline $\mathrm{J} 14-3 \times \mathrm{RF}$ & 3.76 & 3.18 & $15.4^{*}$ & 57 & 41 & 28.0 & 90 & 79 & 12.5 \\
\hline $\mathrm{OB} \times \mathrm{RF}$ & 3.62 & 3.18 & $12.2 *$ & 54 & 43 & 21.0 & 103 & 83 & 19.0 \\
\hline $\mathrm{SC} \times \mathrm{J} 14-3$ & 3.72 & 3.13 & $15.9^{*}$ & 87 & 65 & 25.6 & 108 & 93 & 13.3 \\
\hline M4-4 × 97/7-2 & 3.7 & 3.16 & $14.6^{*}$ & - & - & - & 45 & 36 & 19.3 \\
\hline $\mathrm{SC} \times 97 / 7-2$ & 3.29 & 2.76 & $16.1 *$ & 63 & 52 & 17.6 & 46 & 37 & 19.1 \\
\hline Mean & 3.82 & 3.22 & $15.7 *$ & 60 & 46 & $23.3 *$ & 77 & 64 & $16.9 *$ \\
\hline
\end{tabular}

Z* Significant between heat shock and control plants at $P \leq 0.05$.

${ }^{y}$ Raw data of flower diameter, petal number, and flower dry weight were used to compare population means in control vs. heat stressed. Only petal number greater than eight was considered.

${ }^{\mathrm{x}} \mathrm{OB}=$ 'Old Blush'; J14-3 = J06-20-14-3; VS = 'Vineyard Song'; SC = 'Sweet Chariot'; LC = 'Little Chief'; RF = 'Red Fairy'.

Table 2. The effect of heat shock ( $1 \mathrm{~h}$ at $44{ }^{\circ} \mathrm{C}$ with $50 \%$ relative humidity) on the population and individual progenies from 10 diploid rose populations.

\begin{tabular}{|c|c|c|c|c|c|c|c|c|c|}
\hline & \multicolumn{3}{|c|}{ Flower diam $(\mathrm{cm})$} & \multicolumn{3}{|c|}{ Petal number } & \multicolumn{3}{|c|}{ Flower dry wt (mg) } \\
\hline Observation & \multicolumn{3}{|c|}{447} & \multicolumn{3}{|c|}{190} & \multicolumn{3}{|c|}{447} \\
\hline \multirow[t]{2}{*}{$r^{2}$} & \multicolumn{3}{|c|}{0.83} & \multicolumn{3}{|c|}{0.85} & \multicolumn{3}{|c|}{0.84} \\
\hline & DF & Variance & $\mathrm{MS}^{\mathrm{y}}$ & DF & Variance & MS & $\mathrm{DF}$ & Variance & MS \\
\hline Population & 9 & 35.50 & $3.94 * * *$ & 7 & 2.70 & $0.39 * * *$ & 9 & 7.90 & $0.88 * * *$ \\
\hline Progeny [Population] & 70 & 62.08 & $0.89 * * *$ & 28 & 6.56 & $0.23 * * *$ & 70 & 8.34 & $0.12 * * *$ \\
\hline Heat shock & 1 & 33.63 & $33.63 * * *$ & 1 & 0.31 & $0.31 * * *$ & 1 & 0.71 & $0.71 * * *$ \\
\hline Population by heat shock & 9 & 2.06 & $0.23 *$ & 7 & 0.21 & $0.03^{\mathrm{NS}}$ & 9 & 0.07 & $0.01^{\mathrm{NS}}$ \\
\hline Progeny [Population] by heat shock & 70 & 12.37 & $0.18 * * *$ & 28 & 0.35 & $0.01^{\mathrm{NS}}$ & 70 & 0.87 & $0.01^{\mathrm{NS}}$ \\
\hline
\end{tabular}

${ }^{\mathrm{z}}$ Raw data of flower diameter, $\log _{10}$ transformed data of petal number, and flower dry weight. Only petal number greater than 8 was considered.

yNs $, * * *, * * *$ Nonsignificant or significant at $P \leq 0.05,0.01$, or 0.001 , respectively.

On a progeny level, 45 showed a decrease in flower diameter because of heatshock treatment; 34 did not change, and one seedling had an increase of flower diameter. Ideally, it is desirable that the flower size does not change throughout the year. This information indicates that this should be possible with proper breeding and selection.

Genetic analysis of flower diameter, petal number, and flower dry weight. The total of the interaction effects can be regarded as a genetic-environment interaction $(\mathrm{G} \times \mathrm{E})$ effect. Because the genetic effect for treatment by female parent effect and the treatment by pollen parent effect in petal number and flower dry weight was less than $0.5 \%$, these two effects were removed in the analysis. The estimated narrow-sense heritability and broad-sense heritability for flower diameter, petal number (only double-flowered genotypes), and petal dry weight (whole flower without the pedicel) were $0.24 /$ $0.62,0.12 / 0.74$, and $0.34 / 0.76$, respectively (Table 3). Thus, all the flower-size traits had a moderate to small narrow-sense heritability and a moderately high broad-sense heritability. Flower diameter was the only flower-size measurement with a positive interaction effect which only accounted for $6.3 \%$ of the variance (Table 3 ) and resulted in a small $\mathrm{Vg}$ $\times e / V g$ ratio $(0.15)$ (Table 3 ). The positive variance explained by the interaction of the flower diameter corresponds to a significant interaction in the ANOVA which indicates flower diameter is the better trait, as compared with petal number or flower dry weight, to select for heat-stable flower size.

Table 3. Genetic variance calculated by restricted estimated maximum likelihood for flower diameter, petal number, and flower dry weight with heat stress in 10 diploid rose populations in the heat-shock experiment $\left(1 \mathrm{~h}, 44^{\circ} \mathrm{C}, 50 \%\right.$ relative humidity).

\begin{tabular}{|c|c|c|c|}
\hline & Flower diam ${ }^{z}$ & Petal number & Flower dry wt \\
\hline \multirow[t]{2}{*}{$\overline{r^{2}}$} & 0.71 & 0.77 & 0.79 \\
\hline & & Percentage of total variance & \\
\hline $\mathrm{FP}^{\mathrm{y}}$ & 2.3 & 7.9 & 3.4 \\
\hline $\mathrm{PP}$ & 14.4 & 2.5 & 28.6 \\
\hline Progeny [FP, PP] & 26.6 & 55.4 & 39.1 \\
\hline Heat shock & 27.0 & 10.5 & 6.0 \\
\hline $\mathrm{HS} \times \mathrm{FP}$ & 0 & - & - \\
\hline $\mathrm{HS} \times \mathrm{PP}$ & 1.1 & - & - \\
\hline \multirow[t]{2}{*}{$\mathrm{P} \times \mathrm{HS}$} & 5.2 & 0 & 0 \\
\hline & & Genetic variance & \\
\hline$V a^{\mathrm{x}}$ & 0.081 & 0.009 & 0.017 \\
\hline$V d$ & 0.129 & 0.048 & 0.020 \\
\hline$V g$ & 0.210 & 0.057 & 0.037 \\
\hline$V p$ & 0.338 & 0.078 & 0.049 \\
\hline$V g \times e$ & 0.031 & 0 & 0 \\
\hline$V g \times e / V g$ & 0.145 & 0 & 0 \\
\hline \multirow[t]{2}{*}{ Verror } & 0.113 & 0.021 & 0.012 \\
\hline & & Heritability & \\
\hline$h^{2}$ & 0.24 & 0.12 & 0.34 \\
\hline$H^{2}$ & 0.62 & 0.74 & 0.76 \\
\hline
\end{tabular}

${ }^{\mathrm{z}}$ Raw data of flower diameter, $\log _{10}$ transformed data of petal number, and flower dry weight were used. Only petal number greater than 8 was considered.

${ }^{\mathrm{y}} \mathrm{FP}=$ female parent; $\mathrm{PP}=$ pollen parent; HS = heat shock; $\mathrm{P} \times \mathrm{HS}=$ progeny [FP, PP] by heat-shock interaction; $H^{2}=$ broad-sense heritability; $h^{2}=$ narrow-sense heritability.

${ }^{\mathrm{x}} V a=$ Parental variances; $V d=$ progeny variance; $V e=$ variance due to the change of environment; $V g=$ variance due to parents and progeny; $V g \times e=$ variance due to the interaction of genotype and environment; $V p($ phenotypic variance $)=(V a+V d+V g \times e / e+$ Verror $) ; h^{2}=V a / V p ; H^{2}=(V a+V d) / V p ; e=$ number of environments.

\section{Discussion}

The heat stress caused by the greenhouse heat-shock treatment caused a $15.7 \%$ to $23.3 \%$ decrease in flower size (Table 1). This agreed with previous studies of both cutflower roses and garden roses that flower diameter and flower dry weight were decreased after heat stress (Greyvenstein, 2013; Greyvenstein et al., 2014; Shin et al., 
2001). In addition, as expected, flower size differed among seedlings and populations (Tables 1 and 2). However, it is the interaction effect which indicates whether the genetic materials differ in heat tolerance. Previous work showed that garden roses differed in their reaction to temperature in the field as measured by flower dry weight with higher temperatures leading to less flower dry weight (Greyvenstein, 2013). The percent decrease in dry weight per $1{ }^{\circ} \mathrm{C}$ increase in temperature $(4.3 \%$ to $6.5 \%)$ differed with the garden rose cultivar examined. In the present study, no differential heatshock responses among populations or seedlings were observed for either petal number or flower dry weight. It was only flower diameter in which differences in heat-stress response (heat tolerance) were detected both on the population and progeny within the population basis.

Previous work using a 3-h heat-shock treatment showed that there was a good correlation between the degree of flower abortion and leaf necrosis and field-heat tolerance ratings based on flower productivity. This suggests that the heat-shock treatment is useful to predict field performance (Greyvenstein, 2013). As the focus of this research was flower size, the heat-shock treatment was designed to affect flower size but not cause flower abortion or leaf necrosis. Consequently, a 1-h heat shock was used instead of a 3-h stress period. Beyond some browning of the pedicels, which may indicate the disruption of the vascular tissue and/or be the initial indications of subsequent flower abortion, the main effect of this treatment was reflected in flower-size changes. Under these conditions, all flower-size parameters showed a large genotypic effect with moderately low narrow-sense $(0.12-0.34)$ and moderately high broad-sense (0.62$0.76)$ heritabilities indicating high nonadditive genetic effects (Table 3 ). This agreed with previous results reported on the genetic effects of petal number and flower diameter (Gitonga et al., 2014; Hibrand-Saint Oyant et al., 2008; Shupert, 2005) and confirms that selection for flower size in the greenhouse on small plants, as is frequently done by commercial rose breeders, is effective.

However, only flower diameter showed a genotype by environmental interaction in the ANOVA and a positive genotype by environmental variance in the genetic analysis. Nevertheless, as this variance is small $(6.3 \%)$ compared with the variance attributed to the genetic effect (43.3\%), the opportunity to select for floral heat tolerance using a 1-h heat-shock $\left(44{ }^{\circ} \mathrm{C}, 50 \% \mathrm{RH}\right)$ approach is limited. Further studies need to confirm preliminary correlations between flower size in the field and on plants grown in pots (Liang, 2016) as well as variation on the heat treatment, which increases the effect on flower size without increasing flower abortion. This might include increasing the time of exposure to $2 \mathrm{~h}$ or lowering the temperature used and raising the time of exposure. The latter approach would better mimic the temperature stress in the field, although it would limit the plants that could be cycled through the heat chamber during the screening process.

\section{Conclusion}

Flower-size parameters which show moderately low narrow-sense heritability $(0.24,0.12$, and 0.34$)$ and moderately high to high broad-sense heritability $(0.62,0.74$, and 0.76 ) for flower diameter, petal number, and flower dry weight, respectively, have been successfully manipulated by rose breeders for centuries via phenotypic selection in both the greenhouse and the field. Unfortunately, heat stress appears to reduce the size and ultimately the flower quality and economic value of rose plants in general. Although the $1-\mathrm{h}$ heat shock $\left(44^{\circ} \mathrm{C}\right)$ reduced flower size in terms of flower diameter, petal number, and flower dry weight, it was only with flower diameter that differences in heat tolerances as indicated by the differential response to the heat shock among populations/progenies $(\mathrm{G} \times \mathrm{E}$ interaction in ANOVA and REML analyses) were detected. As flower diameter shows the most consistent population-based differential response to heat stress, the highest $\mathrm{G} \times \mathrm{E}$ genetic variance $(6.3 \%$ of total variance), is easy to measure in the field and is the most visible trait from a consumer perspective, it may be the best flower size trait to use for the selection of heat-tolerant roses. However, given the low $\mathrm{G} \times \mathrm{E}$ variance, the 1 -h heatshock approach may not be an effective approach for the selection of floral heattolerant rose cultivars. Further work should be done to see if a longer or milder heat shock with greater time exposure might be more useful.

\section{Literature Cited}

Ahmad, I., J.M. Dole, M.A. Khan, M. Qasim, T. Ahmad, and A.S. Khan. 2010. Present status and future prospects of cut rose production in Punjab, Pakistan. HortTechnology 20:1010 1015.

Bernardo, R. 2010. Breeding for quantitative traits in plants. 2nd ed. Stemma Press, Woodbury, MN.

Byrne, D.H., N. Anderson, M. Orwat, and V. Soules. 2010. Field assessment of black spot resistance in roses in a hot humid climate. Acta Hort. 870:115-120.

Connor, A.M., M.J. Stephens, H.K. Hall, and P.A. Alspach. 2005. Variation and heritabilities of antioxidant activity and total phenolic content estimated from a red raspberry factorial experiment. J. Amer. Soc. Hort. Sci. 130:403-411.

Debener, T. 1999. Genetic analysis of horticulturally important morphological and physiological characters in diploid roses. Gartenbauwissenschaft 64:14-19.

Gitonga, V.W., C.F. Koning-Boucoiran, K. Verlinden, O. Dolstra, R.G. Visser, C. Maliepaard, and F.A. Krens. 2014. Genetic variation, heritability and genotype by environment interaction of morphological traits in a tetraploid rose population. BioMed Central Genet. 15:146-159.

Greyvenstein, O.F.C. 2013. Phenotyping of high temperature susceptibility in garden roses (Rosa $\times$ hybrida). Texas A\&M Univ., College Station, TX, PhD Diss.
Greyvenstein, O.F.C., H.B. Pemberton, T.W. Starman, G. Niu, and D.H. Byrne. 2014. Effect of two-week high-temperature treatment on flower quality and abscission of Rosa L. 'Belinda's dream' and 'RADrazz' (Knock$\mathrm{Out}^{\circledR}$ ) under controlled growing environments. HortScience 49:701-705.

Grossi, S.J.A., H.B. Pemberton, and H.J. Lang. 2004. Influence of cultivar and seasonal growing environment on growth and postharvest characteristics of single-shoot pot rose plants. HortScience 39:138-141.

Hallauer, A.R., M.J. Carena, and J.B. Miranda Filho. 2010. Means and variances, p. 33-67. In: A.R. Hallauer, M.J. Carena, and J.B. Miranda Filho (eds.). Quantitative genetics in maize breeding. Springer Science Business Media, New York, NY.

Heinrichs, F. 2008. International statistics flower and plants. Intl. Assn. Hort. Producers 56:1690.

Hibrand-Saint Oyant, L., L. Crespel, S. Rajapakse, L. Zhang, and F. Foucher. 2008. Genetic linkage maps of rose constructed with new microsatellite markers and locating QTL controlling flowering traits. Tree Genet. Genomes 4:11-23.

Holland, J.B., W.E. Nyquist, and C.T. CervantesMartínez. 2003. Estimating and interpreting heritability for plant breeding: An update. Plant Breed. Rev. 22:9-112.

Hutton, S. 2012. The future of the rose industry. Amer. Rose 41:36-37.

Krussmann, G. 1981. The complete book of roses. Timber Press, Portland, OR.

Liang, S. 2016. Changes in flower size and number under heat stress in rose (Rosa $x$ hybrida). Texas A\&M Univ., College Station, TX, MS Diss.

Ma, N., W. Chen, T. Fan, Y. Tian, S. Zhang, D. Zeng, and Y. Li. 2015. Low temperatureinduced DNA hypermethylation attenuates expression of RhAG, an AGAMOUS homolog, and increases petal number in rose (Rosa hybrida). BioMed Central Plant Biology 15:237-249.

Marissen, N. 2001. Effects of pre-harvest light intensity and temperature on carbohydrate levels and vase life of cut roses. Acta Hort. 543:331-336.

Moe, R. 1975. The effect of growing temperature on keeping quality of cut roses. Acta Hort. 41:77-92.

NOAA. 2015. Climate data, date range 1 July 2013 to 20 Dec. 2015. National Centers for Environmental Information. 30 Dec. 2015. <http:// www.ncdc.noaa.gov/cdo-web/search>.

Pemberton, H.B. and J.F. Karlik. 2015. A recent history of changing trends in USA garden rose plant sales, types, and production methods. Acta Hort. 1064:223-234.

Shepherd, R.E. 1954. History of the Rose. Macmillan, New York, NY.

Shin, H.K., J.H. Lieth, and S.H. Kim. 2001. Effects of temperature on leaf area and flower size in rose. Acta Hort. 547:185-191.

Shupert, D. 2005. The inheritance of several traits in three diploid interspecific rose populations. Texas A\&M Univ., College Station, TX, MS Diss.

Vineland Research and Innovation Centre. 2013. The innovation report. Vineland Research and Innovation Centre. Vineland Station, ON, Canada. p. 1-23.

Wahid, A., S. Gelani, M. Ashraf, and M. Foolad. 2007. Heat tolerance in plants: An overview. Environ. Expt. Bot. 61:199-223.

Zlesak, D.C. 2006. Rosa, p. 695-740. In: N. Anderson (eds.). Flower breeding and genetics. Springer, Amsterdam, Netherlands. 